\title{
Some Common Fixed-Point Theorems for Generalized-Contractive-Type Mappings on Complex-Valued Metric Spaces
}

\author{
Chakkrid Klin-eam and Cholatis Suanoom \\ Department of Mathematics, Faculty of Science, Naresuan University, Phitsanulok 65000, Thailand \\ Correspondence should be addressed to Chakkrid Klin-eam; chakkridk@nu.ac.th
}

Received 14 December 2012; Accepted 9 March 2013

Academic Editor: Somyot Plubtieng

Copyright (C) 2013 C. Klin-eam and C. Suanoom. This is an open access article distributed under the Creative Commons Attribution License, which permits unrestricted use, distribution, and reproduction in any medium, provided the original work is properly cited.

Fixed-point theory in complex valued metric spaces has greatly developed in recent times. In this paper, we prove certain common fixed-point theorems for two single-valued mappings in such spaces. The mappings we consider here are assumed to satisfy certain metric inequalities with generalized fixed-point theorems due to Rouzkard and Imdad (2012). This extends and subsumes many results of other authors which were obtained for mappings on complex-valued metric spaces.

\section{Introduction}

The existence and uniqueness of fixed-point theorems of operators or mappings has been a subject of great interest since the work of Banach in 1992 [1]. The Banach contraction mapping principle is widely recognized as the source of metric fixed-point theory. A mapping $T: X \rightarrow X$, where $(X, d)$ is a metric space, is said to be a contraction mapping if for all $x, y \in X$,

$$
d(T x, T y) \leq \lambda d(x, y), \quad \text { where } 0<\lambda<1 .
$$

According to the Banach contraction mapping principle, any mapping $T$ satisfying (1) in a complete metric space will have a unique fixed point. This principle includes different directions in different spaces adopted by mathematicians; for example, metric spaces, $G$-metric spaces, partial metric spaces, cone metric spaces, quasimetric spaces have already been obtained.

A new space called the complex-valued metric space which is more general than well-known metric spaces has been introduced by Azam et al. [2]. Azam proved some fixed-point theorems for mappings satisfying a rational inequality. Naturally, this new idea can be utilized to define complex-valued normed spaces and complex-valued inner product spaces which, in turn, offer a wide scope for further investigation. Several authors studied many common fixed point results on complex-valued metric spaces (see [3-5]).

In 2012, Rouzkard and Imdad [6] extended and improved the common fixed-point theorems which are more general than the result of Azam et al. [2].

Theorem 1 (see [6, Theorem 1]). If $S$ and $T$ are self-mappings defined on a complete complex-valued metric space $(X, d)$ satisfying the condition

$$
\begin{aligned}
d(S x, T y) \lesssim & \lambda d(x, y)+\frac{\mu d(x, S x) d(y, T y)}{1+d(x, y)} \\
+ & \frac{\gamma d(y, S x) d(x, T y)}{1+d(x, y)}
\end{aligned}
$$

for all $x, y \in X$ where $\lambda$, $\mu$, and $\gamma$ are nonnegative with $\lambda+\mu+$ $\gamma<1$, then $S$ and $T$ have a unique common fixed point.

Though complex-valued metric spaces from a spacial class of cone metric spaces, yet this idea is intended to define rational expressions which are not meaningful in cone metric spaces, and thus many results of analysis cannot be generalized to cone metric spaces. The aim of this paper is to establish some common fixed-point theorems for two nonlinear general contraction mappings in complex-valued metric spaces. Our results generalized Theorem 1. 


\section{Preliminaries}

Let $\mathbb{C}$ be the set of complex numbers and $z_{1}, z_{2} \in \mathbb{C}$, we define a partial order $\prec$ and $\lesssim$ on $\mathbb{C}$ as follows:

(i) $z_{1} \prec z_{2}$ if and only if $\operatorname{Re}\left(z_{1}\right)<\operatorname{Re}\left(z_{2}\right)$ and $\operatorname{Im}\left(z_{1}\right)<$ $\operatorname{Im}\left(z_{2}\right)$

(ii) $z_{1} \lesssim z_{2}$ if and only if $\operatorname{Re}\left(z_{1}\right) \leq \operatorname{Re}\left(z_{2}\right)$ and $\operatorname{Im}\left(z_{1}\right) \leq$ $\operatorname{Im}\left(z_{2}\right)$.

Now, we briefly review the notation about complex valued metric space and some lemma for prove our main results.

Definition 2. Let $X$ be a nonempty set. Suppose that the mapping $d: X \times X \rightarrow \mathbb{C}$ satisfies the following conditions:

$\left(\mathrm{d}_{1}\right) 0 \lesssim d(x, y)$ for all $x, y \in X$;

$\left(\mathrm{d}_{2}\right) d(x, y)=0$ if and only if $x=y$ for all $x, y \in X$;

$\left(\mathrm{d}_{3}\right) d(x, y)=d(y, x)$ for all $x, y \in X$;

$\left(\mathrm{d}_{4}\right) d(x, y) \precsim d(x, z)+d(z, y)$ for all $x, y, z \in X$.

Then, $d$ is called a complex-valued metric on $X$, and $(X, d)$ is called a complex valued metric space.

Definition 3. Let $(X, d)$ be a complex-valued metric space.

(i) A point $x \in X$ is called interior point of a set $B \subseteq X$ whenever there exists $0 \prec r \in \mathbb{C}$ such that $N(x, r):=$ $\{y \in X: d(x, y) \prec r\} \subseteq B$.

(ii) A point $x \in X$ is called limit point of a set $B \subseteq X$ whenever for every $0 \prec r \in \mathbb{C}$ such that $N(x, y) \cap$ $(X-B) \neq \emptyset$.

(iii) A subset $B \subseteq X$ is called open whenever each element of $B$ is an interior point of $B$.

(iv) A subset $B \subseteq X$ is called closed whenever each limit point of $B$ belongs to $B$.

(v) The family $F=\{N(x, r): x \in X, 0 \prec r\}$ is a subbasis for a topology on $X$. We denote this complex topology by $\tau_{c}$. Indeed, the topology $\tau_{c}$ is Hausdorff.

Definition 4 (see [2]). Let $(X, d)$ be a complex-valued metric space, and let $\left\{x_{n}\right\}$ be a sequence in $X$ and $x \in X$.

(i) If for every $c \in \mathbb{C}$, with $0 \prec c$ there is $N \in \mathbb{N}$ such that for all $n>N, d\left(x_{n}, x\right) \prec c$, then $\left\{x_{n}\right\}$ is said to be convergent, $\left\{x_{n}\right\}$ converges to $x$ and $x$ is limit point of $\left\{x_{n}\right\}$. We denote this by $x_{n} \rightarrow x$ as $n \rightarrow \infty$ or $\lim _{n \rightarrow \infty} x_{n}=x$.

(ii) If for every $c \in \mathbb{C}$, with $0 \prec c$ there is $N \in \mathbb{N}$ such that for all $n>N, d\left(x_{n}, x_{n+m}\right) \prec c$, where $m \in \mathbb{N}$, then $\left\{x_{n}\right\}$ is said to be Cauchy sequence.

(iii) If every Cauchy sequence in $X$ is convergent, then $(X, d)$ is said to be a complete complex-valued metric space.

Lemma 5 (see [2]). Let $(X, d)$ be a complex-valued metric space, and let $\left\{x_{n}\right\}$ be a sequence in $X$. Then, $\left\{x_{n}\right\}$ converges to $x$ if and only if $\left|d\left(x_{n}, x\right)\right| \rightarrow 0$ as $n \rightarrow \infty$.
Lemma 6 (see [2]). Let $(X, d)$ be a complex-valued metric space, and let $\left\{x_{n}\right\}$ be a sequence in $X$. Then, $\left\{x_{n}\right\}$ is a Cauchy sequence if and only if $\left|d\left(x_{n}, x_{n+m}\right)\right| \rightarrow 0$ as $n \rightarrow \infty$, where $m \in \mathbb{N}$.

Definition 7. Two families of self-mappings $\left\{T_{i}\right\}_{i=1}^{m}$ and $\left\{S_{i}\right\}_{i=1}^{n}$ are said to be pairwise commuting if:

(i) $T_{i} T_{j}=T_{j} T_{i}, i, j \in\{1,2, \ldots, m\}$.

(ii) $S_{i} S_{j}=S_{j} S_{i}, i, j \in\{1,2, \ldots, n\}$.

(iii) $T_{i} S_{j}=S_{j} T_{i}, i \in\{1,2, \ldots, m\}, j \in\{1,2, \ldots, n\}$.

Definition 8. Let $S$ and $T$ be self-mappings of a nonempty set $X$.

(i) A point $x \in X$ is said to be a fixed point of $T$ if $T x=x$.

(ii) A point $x \in X$ is said to be a common fixed point of $T$ and $S$ if $T x=S x=x$.

Remark 9. We obtain that the following statements hold:

(i) If $z_{1} \precsim z_{2}$ and $z_{2} \precsim z_{3}$, then $z_{1} \precsim z_{3}$.

(ii) If $z \in \mathbb{C}, a, b \in \mathbb{R}$, and $a \leq b$, then $a z \lesssim b z$.

(iii) If $0 \precsim z_{1} \precsim z_{2}$, then $\left|z_{1}\right| \leq\left|z_{2}\right|$.

\section{Main Results}

In this section, we will prove some common fixed-point theorems for the generalized contractive mappings in complexvalued metric space.

Theorem 10. If $S$ and $T$ are self-mappings defined on a complete complex valued metric space $(X, d)$ satisfying the condition

$$
\begin{aligned}
d(S x, T y) \lesssim & A d(x, y)+\frac{B d(x, S x) d(y, T y)}{1+d(x, y)} \\
& +\frac{C d(y, S x) d(x, T y)}{1+d(x, y)} \\
& +\frac{D d(x, S x) d(x, T y)}{1+d(x, y)}+\frac{E d(y, S x) d(y, T y)}{1+d(x, y)}
\end{aligned}
$$

for all $x, y \in X$, where $A, B, C, D$, and $E$ are nonnegative with $A+B+C+2 D+2 E<1$, then $S$ and $T$ have a unique common fixed point.

Proof. Let $x_{0}$ be an arbitrary in $X$. Since $S(X) \subseteq X$ and $T(X) \subseteq X$, we construct the sequence $\left\{x_{k}\right\}$ in $X$ such that 
$x_{2 k+1}=S x_{2 k}$ and $x_{2 k+2}=T x_{2 k+1}$ for all $k \geq 0$. From the definition of $\left\{x_{k}\right\}$ and (3), we obtain that

$$
\begin{aligned}
d\left(x_{2 k+1}, x_{2 k+2}\right)= & d\left(S x_{2 k}, T x_{2 k+1}\right) \\
\lesssim & A d\left(x_{2 k}, x_{2 k+1}\right) \\
& +\frac{B d\left(x_{2 k}, S x_{2 k}\right) d\left(x_{2 k+1}, T x_{2 k+1}\right)}{1+d\left(x_{2 k}, x_{2 k+1}\right)} \\
& +\frac{C d\left(x_{2 k+1}, S x_{2 k}\right) d\left(x_{2 k}, T x_{2 k+1}\right)}{1+d\left(x_{2 k}, x_{2 k+1}\right)} \\
& +\frac{D d\left(x_{2 k}, S x_{2 k}\right) d\left(x_{2 k}, T x_{2 k+1}\right)}{1+d\left(x_{2 k}, x_{2 k+1}\right)} \\
& +\frac{E d\left(x_{2 k+1}, S x_{2 k}\right) d\left(x_{2 k+1}, T x_{2 k+1}\right)}{1+d\left(x_{2 k}, x_{2 k+1}\right)} .
\end{aligned}
$$

Since $x_{2 k+1}=S x_{2 k}$ implies that $d\left(x_{2 k+1}, S x_{2 k}\right)=0$; therefore,

$$
\begin{aligned}
d\left(x_{2 k+1}, x_{2 k+2}\right) \lesssim & A d\left(x_{2 k}, x_{2 k+1}\right) \\
& +\frac{B d\left(x_{2 k}, S x_{2 k}\right) d\left(x_{2 k+1}, T x_{2 k+1}\right)}{1+d\left(x_{2 k}, x_{2 k+1}\right)} \\
& +\frac{D d\left(x_{2 k}, S x_{2 k}\right) d\left(x_{2 k}, T x_{2 k+1}\right)}{1+d\left(x_{2 k}, x_{2 k+1}\right)},
\end{aligned}
$$

by Remark 9 and $\left|1+d\left(x_{2 k}, x_{2 k+1}\right)\right|>\left|d\left(x_{2 k}, x_{2 k+1}\right)\right|$, we have

$$
\begin{aligned}
\left|d\left(x_{2 k+1}, x_{2 k+2}\right)\right| \leq & A\left|d\left(x_{2 k}, x_{2 k+1}\right)\right| \\
& +\frac{B\left|d\left(x_{2 k}, S x_{2 k}\right)\right|\left|d\left(x_{2 k+1}, T x_{2 k+1}\right)\right|}{\left|1+d\left(x_{2 k}, x_{2 k+1}\right)\right|} \\
& +\frac{D\left|d\left(x_{2 k}, S x_{2 k}\right)\right|\left|d\left(x_{2 k}, T x_{2 k+1}\right)\right|}{\left|1+d\left(x_{2 k}, x_{2 k+1}\right)\right|} \\
= & A\left|d\left(x_{2 k}, x_{2 k+1}\right)\right| \\
& +B\left|d\left(x_{2 k+1}, x_{2 k+2}\right)\right| \frac{\left|d\left(x_{2 k}, x_{2 k+1}\right)\right|}{\left|1+d\left(x_{2 k}, x_{2 k+1}\right)\right|} \\
& +D\left|d\left(x_{2 k}, x_{2 k+2}\right)\right| \frac{\left|d\left(x_{2 k}, x_{2 k+1}\right)\right|}{\left|1+d\left(x_{2 k}, x_{2 k+1}\right)\right|} \\
< & A\left|d\left(x_{2 k}, x_{2 k+1}\right)\right|+B\left|d\left(x_{2 k+1}, x_{2 k+2}\right)\right| \\
& +D\left|d\left(x_{2 k}, x_{2 k+2}\right)\right| .
\end{aligned}
$$

From (6) and Definition 2, we have

$$
\begin{aligned}
\left|d\left(x_{2 k+1}, x_{2 k+2}\right)\right|< & A\left|d\left(x_{2 k}, x_{2 k+1}\right)\right|+B\left|d\left(x_{2 k+1}, x_{2 k+2}\right)\right| \\
& +D\left|d\left(x_{2 k}, x_{2 k+1}\right)\right|+D\left|d\left(x_{2 k+1}, x_{2 k+2}\right)\right|
\end{aligned}
$$

it follows that $\left|d\left(x_{2 k+1}, x_{2 k+2}\right)\right|<((A+D) /(1-B-$ D) $)\left|d\left(x_{2 k}, x_{2 k+1}\right)\right|$.
Similarly, we get

$$
\begin{aligned}
d\left(x_{2 k+2}, x_{2 k+3}\right)= & d\left(x_{2 k+3}, x_{2 k+2}\right)=d\left(S x_{2 k+2}, T x_{2 k+1}\right) \\
\lesssim & A d\left(x_{2 k+2}, x_{2 k+1}\right) \\
& +\frac{B d\left(x_{2 k+2}, S x_{2 k+2}\right) d\left(x_{2 k+1}, T x_{2 k+1}\right)}{1+d\left(x_{2 k+2}, x_{2 k+1}\right)} \\
& +\frac{C d\left(x_{2 k+1}, S x_{2 k+2}\right) d\left(x_{2 k+2}, T x_{2 k+1}\right)}{1+d\left(x_{2 k+2}, x_{2 k+1}\right)} \\
& +\frac{D d\left(x_{2 k+2}, S x_{2 k+2}\right) d\left(x_{2 k+2}, T x_{2 k+1}\right)}{1+d\left(x_{2 k+2}, x_{2 k+1}\right)} \\
& +\frac{E d\left(x_{2 k+1}, S x_{2 k+2}\right) d\left(x_{2 k+1}, T x_{2 k+1}\right)}{1+d\left(x_{2 k+2}, x_{2 k+1}\right)} .
\end{aligned}
$$

Since $x_{2 k+2}=T x_{2 k+1}$ implies that $d\left(x_{2 k+2} T x_{2 k+1}\right)=0$; therefore,

$$
\begin{aligned}
d\left(x_{2 k+2}, x_{2 k+3}\right) \lesssim & A d\left(x_{2 k+2}, x_{2 k+1}\right) \\
& +\frac{B d\left(x_{2 k+2}, S x_{2 k+2}\right) d\left(x_{2 k+1}, T x_{2 k+1}\right)}{1+d\left(x_{2 k+2}, x_{2 k+1}\right)} \\
& +\frac{E d\left(x_{2 k+1}, S x_{2 k+2}\right) d\left(x_{2 k+1}, T x_{2 k+1}\right)}{1+d\left(x_{2 k+2}, x_{2 k+1}\right)}
\end{aligned}
$$

by Remark 9 and $\left|1+d\left(x_{2 k+2}, x_{2 k+1}\right)\right|>\left|d\left(x_{2 k+2}, x_{2 k+1}\right)\right|$, we have

$$
\begin{aligned}
\left|d\left(x_{2 k+2}, x_{2 k+3}\right)\right| & \\
\leq & A\left|d\left(x_{2 k+2}, x_{2 k+1}\right)\right| \\
& +\frac{B\left|d\left(x_{2 k+2}, S x_{2 k+2}\right)\right|\left|d\left(x_{2 k+1}, T x_{2 k+1}\right)\right|}{\left|1+d\left(x_{2 k+2}, x_{2 k+1}\right)\right|} \\
& +\frac{E\left|d\left(x_{2 k+1}, S x_{2 k+2}\right)\right|\left|d\left(x_{2 k+1}, T x_{2 k+1}\right)\right|}{\left|1+d\left(x_{2 k+2}, x_{2 k+1}\right)\right|} \\
= & A\left|d\left(x_{2 k+2}, x_{2 k+1}\right)\right| \\
& +B\left|d\left(x_{2 k+2}, x_{2 k+3}\right)\right| \frac{\left|d\left(x_{2 k+1}, x_{2 k+2}\right)\right|}{\left|1+d\left(x_{2 k+2}, x_{2 k+1}\right)\right|} \\
& +E\left|d\left(x_{2 k+1}, x_{2 k+3}\right)\right| \frac{\left|d\left(x_{2 k+1}, x_{2 k+2}\right)\right|}{\left|1+d\left(x_{2 k+2}, x_{2 k+1}\right)\right|} \\
< & A\left|d\left(x_{2 k+2}, x_{2 k+1}\right)\right|+B\left|d\left(x_{2 k+2}, x_{2 k+3}\right)\right| \\
+ & E\left|d\left(x_{2 k+1}, x_{2 k+3}\right)\right| .
\end{aligned}
$$

From (10) and Definition 2, we have

$$
\begin{aligned}
\left|d\left(x_{2 k+1}, x_{2 k+2}\right)\right|< & A\left|d\left(x_{2 k+2}, x_{2 k+1}\right)\right|+B\left|d\left(x_{2 k+2}, x_{2 k+3}\right)\right| \\
& +E\left|d\left(x_{2 k+1}, x_{2 k+2}\right)\right| \\
& +D\left|d\left(x_{2 k+2}, x_{2 k+3}\right)\right|
\end{aligned}
$$


it follows that $\left|d\left(x_{2 k+2}, x_{2 k+3}\right)\right|<((A+E) /(1-B-$ E)) $\left|d\left(x_{2 k+1}, x_{2 k+2}\right)\right|$.

Putting $k=\max \{((A+D) /(1-B-D)),((A+E) /(1-B-$ $E))\}$, we obtain that

$$
\begin{aligned}
\left|d\left(x_{n}, x_{n+1}\right)\right| & \leq k\left|d\left(x_{n-1}, x_{n}\right)\right| \leq k^{2}\left|d\left(x_{n-2}, x_{n-1}\right)\right| \\
& \leq \cdots \leq k^{n}\left|d\left(x_{0}, x_{1}\right)\right| \quad \forall n .
\end{aligned}
$$

Thus, for any $n \in \mathbb{N}$, we have

$$
\begin{aligned}
\left|d\left(x_{n}, x_{m}\right)\right| & \leq\left|d\left(x_{n}, x_{n+1}\right)\right| \leq\left|d\left(x_{n+1}, x_{n+2}\right)\right| \\
& \leq \cdots \leq\left|d\left(x_{m-1}, x_{m}\right)\right| \\
& \leq\left(k^{n}+k^{n+1}+k^{n+2}+\cdots+k^{m-1}\right)\left|d\left(x_{0}, x_{1}\right)\right| \\
& \leq\left(\frac{k^{n}}{1-k}\right)\left|d\left(x_{0}, x_{1}\right)\right|
\end{aligned}
$$

it follows that $\left|d\left(x_{n}, x_{m}\right)\right| \leq\left(k^{n} /(1-k)\right)\left|d\left(x_{0}, x_{1}\right)\right| \rightarrow 0$ as $n \rightarrow \infty$.

By Lemma 6, the sequence $\left\{x_{n}\right\}$ is a Cauchy. Since $X$ is compete, there exists a point $z \in X$ such that $x_{n} \rightarrow z$ as $n \rightarrow \infty$.

Next, we will show that $S z=z$. By the notion of a complete complex-valued metric $d$, we have

$$
\begin{aligned}
d(z, S z) \lesssim & d\left(z, x_{2 k+2}\right)+d\left(x_{2 k+2}, S z\right) \\
= & d\left(z, x_{2 k+2}\right)+d\left(S z, T x_{2 k+1}\right) \\
\lesssim & d\left(z, x_{2 k+2}\right)+A d\left(z, x_{2 k+1}\right) \\
& +\frac{B d(z, S z) d\left(x_{2 k+1}, T x_{2 k+1}\right)}{1+d\left(z, x_{2 k+1}\right)} \\
& +\frac{C d\left(x_{2 k+1}, S z\right) d\left(z, T x_{2 k+1}\right)}{1+d\left(z, x_{2 k+1}\right)} \\
& +\frac{D d(z, S z) d\left(z, T x_{2 k+1}\right)}{1+d\left(z, x_{2 k+1}\right)} \\
& +\frac{E d\left(x_{2 k+1}, S z\right) d\left(x_{2 k+1}, T x_{2 k+1}\right)}{1+d\left(z, x_{2 k+1}\right)}
\end{aligned}
$$

which implies that

$$
\begin{aligned}
|d(z, S z)| \leq & \left|d\left(z, x_{2 k+2}\right)\right|+A\left|d\left(z, x_{2 k+1}\right)\right| \\
& +\frac{B|d(z, S z)|\left|d\left(x_{2 k+1}, x_{2 k+2}\right)\right|}{\left|1+d\left(z, x_{2 k+1}\right)\right|} \\
& +\frac{C\left|d\left(x_{2 k+1}, S z\right)\right|\left|d\left(z, x_{2 k+2}\right)\right|}{\left|1+d\left(z, x_{2 k+1}\right)\right|} \\
& +\frac{D|d(z, S z)|\left|d\left(z, x_{2 k+2}\right)\right|}{\left|1+d\left(z, x_{2 k+1}\right)\right|} \\
& +\frac{E\left|d\left(x_{2 k+1}, S z\right)\right|\left|d\left(x_{2 k+1}, x_{2 k+2}\right)\right|}{\left|1+d\left(z, x_{2 k+1}\right)\right|} .
\end{aligned}
$$

Taking $k \rightarrow \infty$, we have $|d(z, S z)|=0$; it is obtained that $d(z, S z)=0$. Thus, $S z=z$. It follows that similarly $T z=z$. Therefore, $z$ is common fixed point of $S$ and $T$.

Finally, to prove the uniqueness of common fixed point, let $z^{*} \in X$ be another common fixed point of $S$ and $T$ such that $S z^{*}=T z^{*}=z^{*}$. Consider

$$
d\left(z, z^{*}\right)=d\left(S z, T z^{*}\right)
$$

$$
\begin{aligned}
\lesssim & A d\left(z, z^{*}\right)+\frac{B d(z, S z) d\left(z^{*}, T z^{*}\right)}{1+d\left(z, z^{*}\right)} \\
+ & \frac{C d\left(z^{*}, S z\right) d\left(z, T z^{*}\right)}{1+d\left(z, z^{*}\right)} \\
+ & \frac{D d(z, S z) d\left(z, T z^{*}\right)}{1+d\left(z, z^{*}\right)} \\
+ & \frac{E d\left(z^{*}, S z\right) d\left(z^{*}, T z^{*}\right)}{1+d\left(z, z^{*}\right)}
\end{aligned}
$$

so that

$$
\begin{aligned}
\left|d\left(z, z^{*}\right)\right| & \leq A\left|d\left(z, z^{*}\right)\right|+\frac{C\left|d\left(z^{*}, S z\right)\right|\left|d\left(z, T z^{*}\right)\right|}{\left|1+d\left(z, z^{*}\right)\right|} \\
& =A\left|d\left(z, z^{*}\right)\right|+C\left|d\left(z^{*}, z\right)\right| \frac{\left|d\left(z, z^{*}\right)\right|}{\left|1+d\left(z, z^{*}\right)\right|} .
\end{aligned}
$$

Since $\left|1+d\left(z, z^{*}\right)\right|>\left|d\left(z, z^{*}\right)\right|$, therefore $\left|d\left(z, z^{*}\right)\right|<$ $A\left|d\left(z, z^{*}\right)\right|+C\left|d\left(z^{*}, z\right)\right|=(A+C)\left|d\left(z, z^{*}\right)\right|$.

This is contradiction to $A+C<1$. Hence, $z=z^{*}$. Therefore, $z$ is a unique common fixed point of $S$ and $T$.

Corollary 11. If $T$ is a self-mapping defined on a complete complex-valued metric space $(X, d)$ satisfying the condition

$$
\begin{aligned}
d(T x, T y) \lesssim & A d(x, y)+\frac{B d(x, T x) d(y, T y)}{1+d(x, y)} \\
& +\frac{C d(y, T x) d(x, T y)}{1+d(x, y)} \\
& +\frac{D d(x, T x) d(x, T y)}{1+d(x, y)}+\frac{E d(y, T x) d(y, T y)}{1+d(x, y)}
\end{aligned}
$$

for all $x, y \in X$, where $A, B, C, D$, and $E$ are nonnegative with $A+B+C+2 D+2 E<1$, then $T$ has a unique fixed point.

Proof. We can prove this result by applying Theorem 10 by setting $T=S$.

Corollary 12. If $S$ and $T$ are self-mappings defined on a complete complex valued metric space $(X, d)$ satisfying the condition

$$
\begin{aligned}
d(S x, T y) \lesssim & A d(x, y)+\frac{B d(x, S x) d(y, T y)}{1+d(x, y)} \\
& +\frac{C d(y, S x) d(x, T y)}{1+d(x, y)}+\frac{D d(x, S x) d(x, T y)}{1+d(x, y)}
\end{aligned}
$$


for all $x, y \in X$, where $A, B, C$, and $D$ are nonnegative with $A+B+C+2 D<1$, then $S$ and $T$ have a unique common fixed point.

Proof. We can prove this result by applying Theorem 10 by setting $E=0$.

Corollary 13. If $T$ is a self-mapping defined on a complete complex valued metric space $(X, d)$ satisfying the condition

$$
\begin{aligned}
d(T x, T y) \lesssim & A d(x, y)+\frac{B d(x, T x) d(y, T y)}{1+d(x, y)} \\
& +\frac{C d(y, T x) d(x, T y)}{1+d(x, y)}+\frac{D d(x, T x) d(x, T y)}{1+d(x, y)}
\end{aligned}
$$

for all $x, y \in X$, where $A, B, C$, and $D$ are nonnegative with $A+B+C+2 D<1$, then $T$ has a unique fixed point.

Proof. We can prove this result by applying Corollary 12 by setting $T=S$ and $E=0$.

Corollary 14. If $S$ and $T$ are self-mappings defined on a complete complex valued metric space $(X, d)$ satisfying the condition

$$
\begin{aligned}
d(S x, T y) \lesssim & A d(x, y)+\frac{B d(x, S x) d(y, T y)}{1+d(x, y)} \\
& +\frac{C d(y, S x) d(x, T y)}{1+d(x, y)}+\frac{E d(y, S x) d(y, T y)}{1+d(x, y)}
\end{aligned}
$$

for all $x, y \in X$ where $A, B, C$, and $E$ are nonnegative with $A+B+C+2 E<1$, then $S$ and $T$ have a unique common fixed point.

Proof. We can prove this result by applying Theorem 10 by setting $D=0$.

Corollary 15. If $T$ is a self-mapping defined on a complete complex valued metric space $(X, d)$ satisfying the condition

$$
\begin{aligned}
d(T x, T y) \lesssim & A d(x, y)+\frac{B d(x, T x) d(y, T y)}{1+d(x, y)} \\
& +\frac{C d(y, T x) d(x, T y)}{1+d(x, y)} \\
& +\frac{D d(x, T x) d(x, T y)}{1+d(x, y)}+\frac{E d(y, T x) d(y, T y)}{1+d(x, y)}
\end{aligned}
$$

for all $x, y \in X$, where $A, B, C$, and $E$ are nonnegative with $A+B+C+2 E<1$, then $T$ has a unique fixed point.
Proof. We can prove this result by applying Corollary 14 by setting $T=S$.

Remark 16. (i) By choosing $D=E=0$ in Theorem 10, we get Theorem 1 of [6].

(ii) By choosing $D=E=0$ and $S=T$ in Theorem 10, we get Corollary 3 of [6].

(iii) By choosing $C=D=E=0$ in Theorem 10, we get Theorem 4 of Azam et al. [2].

(iv) By choosing $C=D=E=0$ and $S=T$ in Theorem 10, we get Corollary 5 of Azam et al. [2].

Theorem 17. If $\left\{T_{i}\right\}_{1}^{m}$ and $\left\{S_{i}\right\}_{1}^{n}$ are two finite pairwise commuting finite families of self-mapping defined on complete complex-valued metric space $(X, d)$ such that the mappings $T$ and $S$ with $T=T_{1} T_{2} \cdots T_{m}$ and $S=S_{1} S_{2} \cdots S_{n}$ satisfy condition (3), then the component maps of the two families $\left\{T_{i}\right\}_{1}^{m}$ and $\left\{S_{i}\right\}_{1}^{n}$ have a unique common fixed point.

Proof. By Theorem 10, one can infer that $T$ and $S$ have a unique common fixed point $Z$ (i.e., $T z=S z=z$ ). Now, we will show that $z$ is a common fixed point of all the component maps of both families. In view of pairwise commutativity of the families $\left\{T_{i}\right\}_{1}^{m}$ and $\left\{S_{i}\right\}_{1}^{n}$, for every $1 \leq k \leq m$, we can write

$$
\begin{aligned}
& T_{k} z=T_{k} S z=S T_{k} z, \\
& T_{k} z=T_{k} T z=T T_{k} z .
\end{aligned}
$$

It implies that $T_{k} z(\forall k)$ is also a common fixed point of $T$ and $S$. By using the uniqueness of common fixed point, we have $T_{k} z=z(\forall k)$. Hence, $z$ is a common fixed point of the family $\left\{T_{i}\right\}_{1}^{m}$. Similarly, we can show that $z$ is a common fixed point of the family $\left\{S_{i}\right\}_{1}^{n}$. This completes the proof of the theorem.

Corollary 18. If $F$ and $G$ are self-mappings defined on $a$ complete complex-valued metric space $(X, d)$ satisfying the condition

$$
\begin{aligned}
d\left(F^{m} x, G^{n} y\right) \lesssim & A d(x, y)+\frac{B d\left(x, F^{m} x\right) d\left(y G^{n} y\right)}{1+d(x, y)} \\
& +\frac{C d\left(y, F^{m} x\right) d\left(x, G^{n} y\right)}{1+d(x, y)} \\
& +\frac{D d\left(x, F^{m} x\right) d\left(x, G^{n} y\right)}{1+d(x, y)} \\
& +\frac{E d\left(y, F^{m} x\right) d\left(y, G^{n} y\right)}{1+d(x, y)}
\end{aligned}
$$

for all $x, y \in X$, where $A, B, C, D$, and $E$ are nonnegative with $A+B+C+2 D+2 E<1$, then $F$ and $G$ have a unique common fixed point.

Proof. We can prove this result by applying Theorem 17 by setting $T_{1}=T_{2}=\cdots=T_{m}=F$ and $S_{1}=S_{2}=\cdots=S_{n}=$ G. 
Corollary 19. If $T$ is a self-mapping defined on a complete complex valued metric space $(X, d)$ satisfying the condition

$$
\begin{aligned}
d\left(T^{n} x, T^{n} y\right) \lesssim & A d(x, y)+\frac{B d\left(x, T^{n} x\right) d\left(y, T^{n} y\right)}{1+d(x, y)} \\
& +\frac{C d\left(y, T^{n} x\right) d\left(x, T^{n} y\right)}{1+d(x, y)} \\
& +\frac{D d\left(x, T^{n} x\right) d\left(x, T^{n} y\right)}{1+d(x, y)} \\
& +\frac{E d\left(y, T^{n} x\right) d\left(y, T^{n} y\right)}{1+d(x, y)}
\end{aligned}
$$

for all $x, y \in X$, where $A, B, C, D$, and $E$ are nonnegative with $A+B+C+2 D+2 E<1$, then $T$ has a unique fixed point.

Proof. We can prove this result by applying Corollary 18 by setting $F=G=T$.

Remark 20. (i) By choosing $D=E=0$ in Theorem 17, we get Theorem 1 of [6].

(ii) By choosing $D=E=0$ in Corollary 18, we get Corollary 6 of [6].

(iii) By choosing $D=E=0$ in Corollary 19 , we get Corollary 7 of [6].

(iv) By choosing $C=D=E=0$ in Corollary 19, we get Corollary 6 of Azam et al. [2].

Corollary 21 (see [5]). If $T: X \rightarrow X$ is a mapping defined on a complete complex-valued metric space $(X, d)$ satisfying the condition

$$
d\left(T^{n} x, T^{n} y\right) \lesssim \lambda d(x, y)
$$

for all $x, y \in X$, where $\lambda$ is nonnegative reals $\lambda<1$, then $T$ has a unique fixed point.

The following example demonstrates the superiority of Bryant theorem [5] over Banach contraction theorem.

Example 22. Let $X=\mathbb{C}$ be the set of complex numbers. Define $d: \mathbb{C} \times \mathbb{C} \rightarrow \mathbb{C}$ as

$$
d\left(z_{1}, z_{2}\right)=\left|x_{1}-x_{2}\right|+i\left|y_{1}-y_{2}\right|,
$$

where $z_{1}=x_{1}+i y_{1}$ and $z_{2}=x_{2}+i y_{2}$. Then, $(\mathbb{C}, d)$ is a complete complex-valued metric space. Define $T: \mathbb{C} \rightarrow \mathbb{C}$ as

$$
T(x+i y)= \begin{cases}0 ; & x, y \in Q, \\ 2+2 i ; & x, y \in Q^{c}, \\ 2 ; & x \in Q^{c}, y \in Q, \\ 2 i ; & x \in Q, y \in Q^{c} .\end{cases}
$$

Now, for $x=1 / \sqrt{3}$ and $y=0$, we get

$$
d\left(T\left(\frac{1}{\sqrt{3}}\right), T(0)\right)=d(2,0)=2 \lesssim \lambda d\left(\frac{1}{\sqrt{3}}, 0\right)=\lambda \frac{1}{\sqrt{3}} .
$$

Thus, $\lambda \geq \sqrt{3}$, which is a contradiction as $0 \leq \lambda<1$. However, notice that $T^{2} z=0$, so that $0=d\left(T^{2} z_{1}, T^{2} z_{2}\right) \precsim$ $\lambda d\left(z_{1}, z_{2}\right)$, which shows that $T^{2}$ satisfies the requirement of Bryant theorem and $z=0$ is the unique fixed point of $T$.

\section{Acknowledgment}

The authors would like to thank the Faculty of Science, Naresuan University, Phitsanulok, Thailand, for the financial support.

\section{References}

[1] S. Banach, "Sur les operations dans les ensembles abstraits et leur application aux equations integrales," Fundamenta Mathematicae, vol. 3, pp. 133-181, 1992.

[2] A. Azam, B. Fisher, and M. Khan, "Common fixed point theorems in complex valued metric spaces," Numerical Functional Analysis and Optimization, vol. 32, no. 3, pp. 243-253, 2011.

[3] S. K. Mohanta and R. Maitra, "Common fixed point of three self mappings in complex valued metric spaces," International Journal of Mathematical Archive, vol. 3, no. 8, pp. 2946-2953, 2012.

[4] W. Sintunavarat and P. Kumam, "Generalized common fixed point theorems in complex valued metric spaces and applications," Journal of Inequalities and Applications, vol. 2012, article 84, 2012.

[5] R. K. Verma and H. K. Pathak, "Common fixed point theorems using property (E.A) in complex-valued metric spaces," Thai Journal of Mathematics, 2012.

[6] F. Rouzkard and M. Imdad, "Some common fixed point theorems on complex valued metric spaces," Computers \& Mathematics with Applications, vol. 64, no. 6, pp. 1866-1874, 2012. 


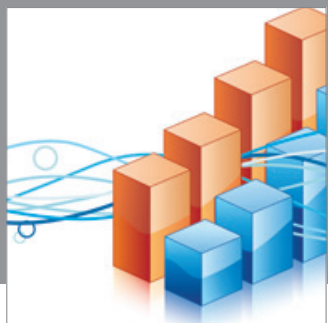

Advances in

Operations Research

mansans

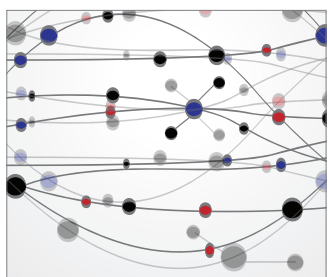

The Scientific World Journal
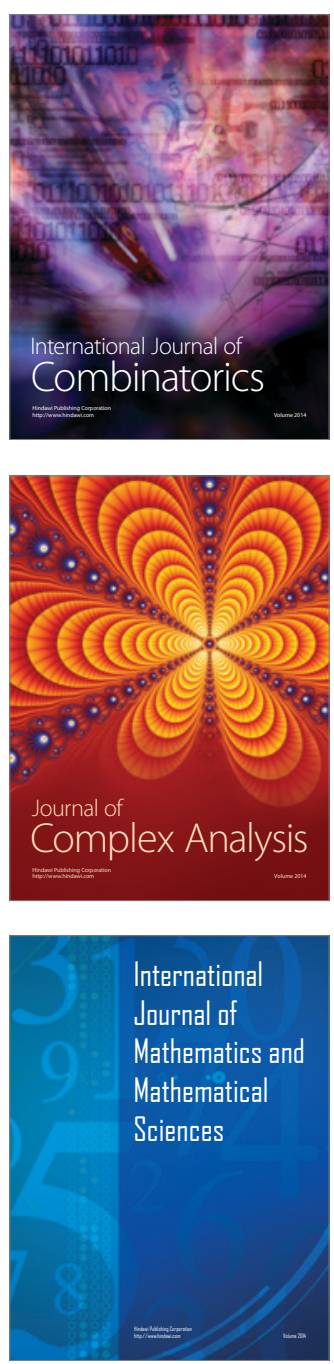
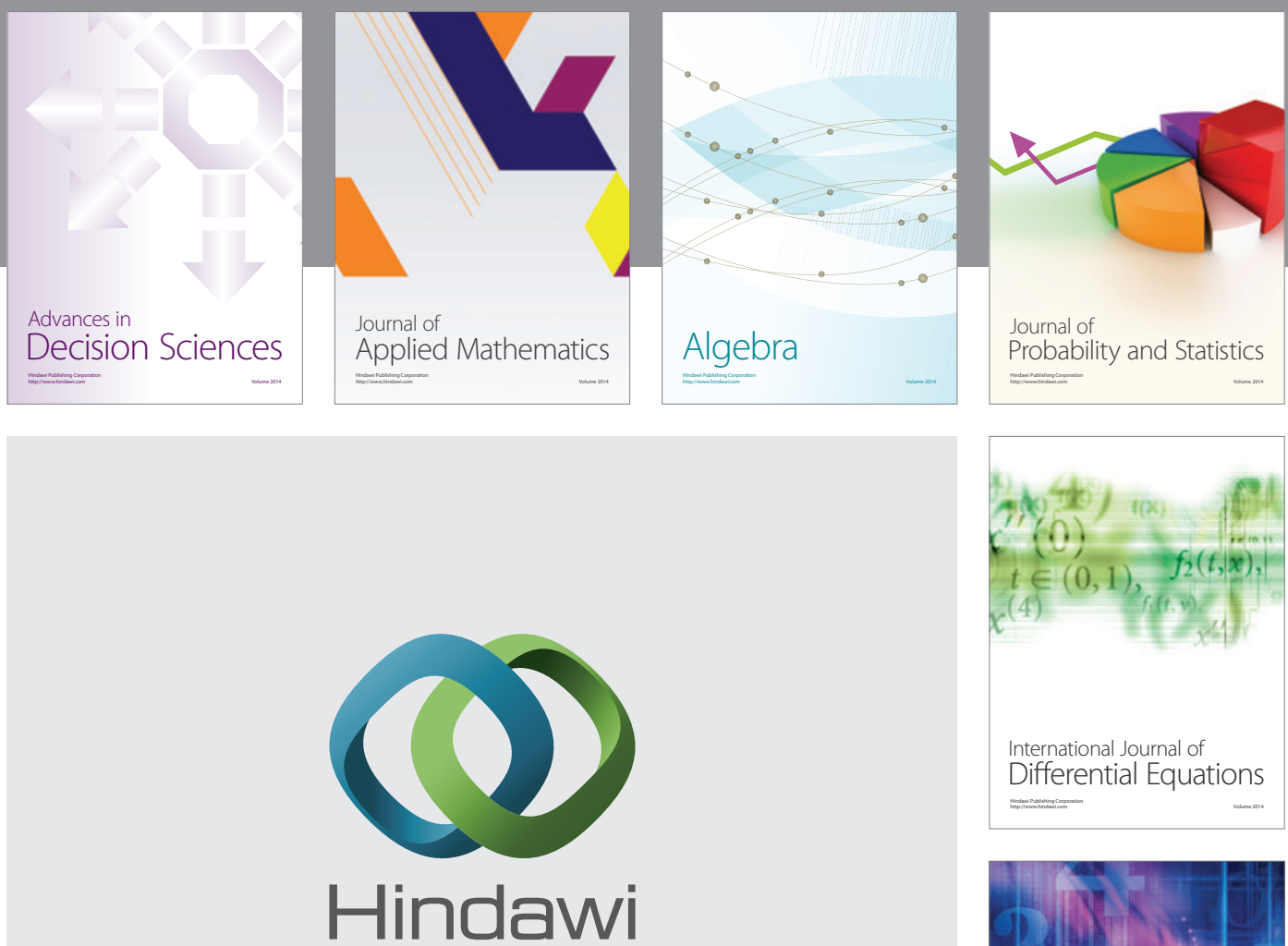

Submit your manuscripts at http://www.hindawi.com
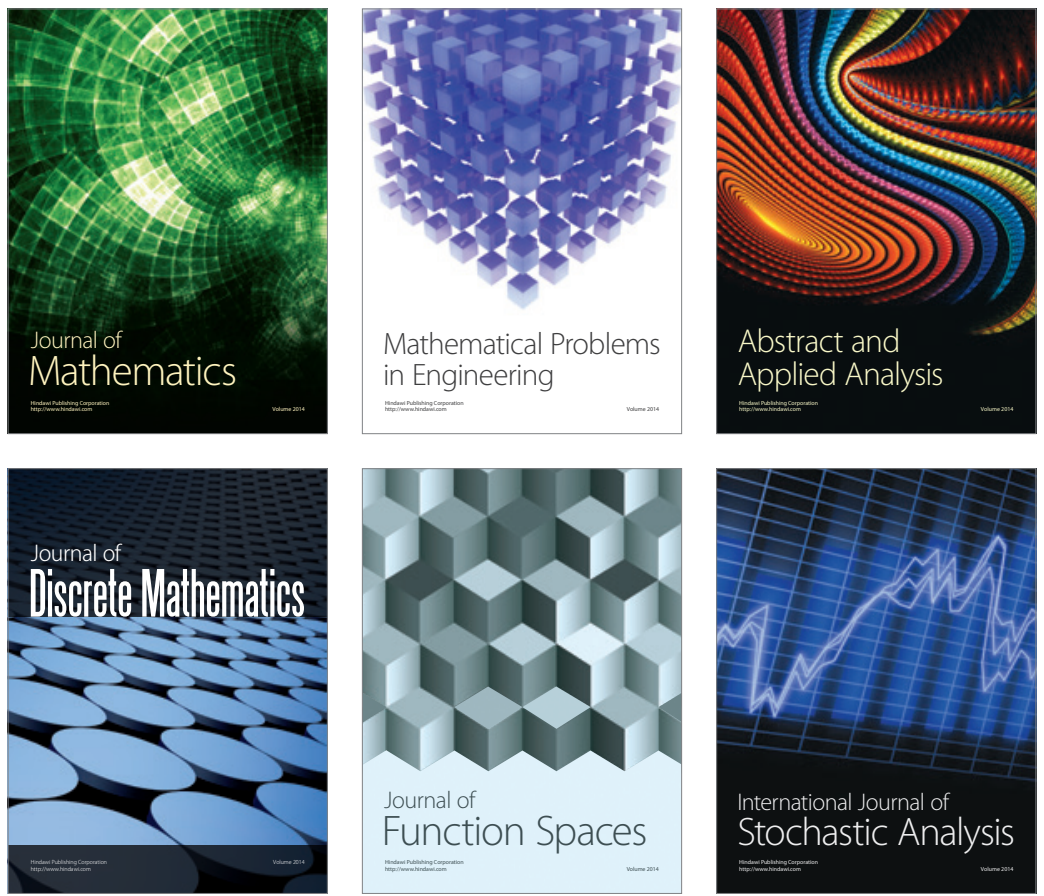

Journal of

Function Spaces

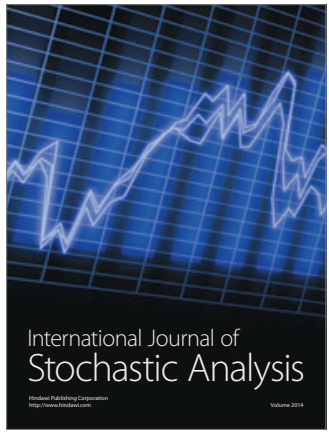

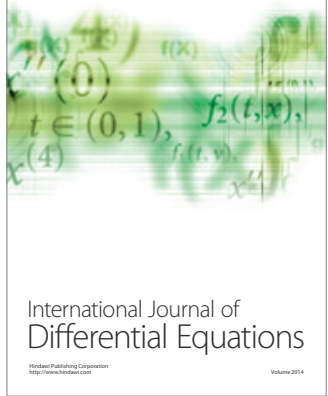
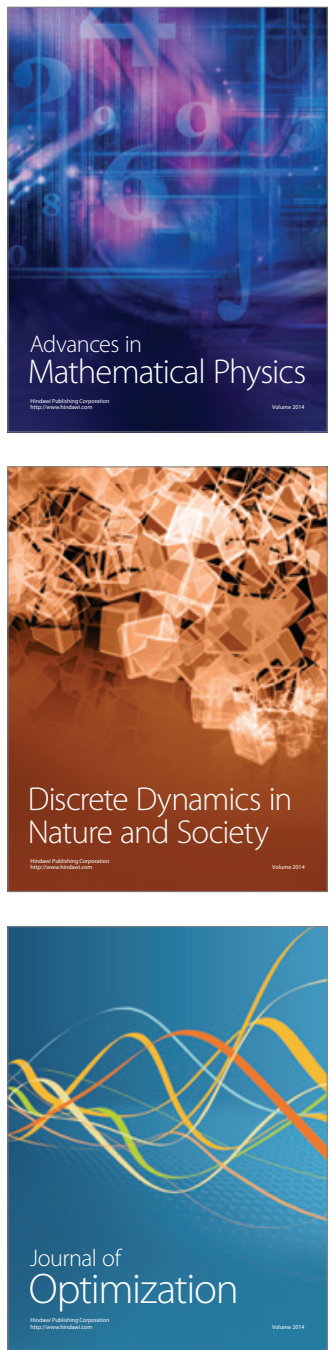